relation to the underlying principles and also in relation to the requirements of practical reinforced concrete construction. The second volume will deal with structures, including foundations, shells and folded plates.

The author's definition of "reinforced concrete" includes presstressed concrete, which is treated as an integral part of the general subject. In addition to giving a lucid account of the theory, he endeavours more particularly to give the reader a measure of real insight into the subject, with the aid of numerous illustrations showing solutions that can suitably be adopted for a variety of standard problems. In this the author draws freely upon his own extensive experience as a design engineer. The importance of this will be appreciated by anyone who has had the misfortune to have been taught reinforced concrete design as a set of arid rules and formulae and subsequently has had to discover, sometimes painfully, that it is possible to obey all the text-book rules and yet commit real "howlers".

The book has two main divisions: I. Materials; II. Structural elements. The first division contains chapters on: concrete and its properties; steel and its properties; protection against attack of various kinds (mechanical, chemical, heat, vibrations, etc.). The second division deals with the following main subjects: design and analysis (general principles for determining stress resultants and dimensions); columns; beams and cantilevers (reinforced concrete, prestressed concrete, composite beams); slabs and floors; walls; joints; bearings and hinges.

The book is well produced, and its subject-matter is set out systematically and clearly. It deals with reinforced concrete and prestressed concrete at what might be called intermediate level, i.e. it has been written with university education in mind, without over-simplifying the subject, on the one hand, and without introducing more than a minimum of mathematics, on the other.

Although the design procedures described are essentially based on the German directives and codes of practice, the book contains so much information of general interest that it can be commended to the attention of any engineering student or practising engineer who is linguistically equipped to read it.

\section{Limit analysis of reinforced concrete slabs} by M. P. Nielsen

Published by Acta Polytechnica Scandinavica, Copenhagen, 1964. pp. 176. Civil Engineering and Building Construction Series No. 26. Price $20.00 \mathrm{~Sv}$. kr.

In this paper, which is a translation of the author's thesis, the reader is assumed to be familiar with the theory of thin plates, the basis of plasticity, tensors, and the earlier works in this field, e.g. Johansen, Ingerslev, Prager and Wood.

Nielsen reviews earlier work mainly in terms of lower-bound or elastic theory, discussing the relevant compatibility, equilibrium, geometrical and boundary conditions. The square yield criterion is justified and extended to orthotropic slabs. Nielsen attempts to deal faithfully with the square yield criterion and maintain the flow rules of Druker, Greenberg and Prager. Thus, near nodes, Nielsen is forced to assume " distributed zones" in which the stress field is infinitely variable and at the same time continuous. In the case of a corner fan it is necessary to show that whatever stress field is invented the load intensity does not become infinite. Nielsen's proof goes no further than to state an equation (6.14) for the statical equivalent of the shear forces and cause certain terms to vanish in the limit and states " if the 'distributed zone' is made infinitely small the statical equivalence of the shear forces in a yield line will be equal to the torsional moment at the point of intersection while the statical equivalence of the torsional moment reduces to zero". Apart from the fact that the mathematical process is suspect, no lower-bound solution could ever be found for such a stress field.

Johansen's intuitive use of curved yield lines is justified mathematically in terms of Nielsen's rules. Finally some lower-bound solutions and a theory of orthotropic plates are developed which are in agreement with the yield criterion.

This paper will be of more use to the student of yield-line theory and the research worker than to the design engineer.

The diagrams are clear and well drawn and are positioned beside the relevant text; this, together with the author's style and clear print, makes the book easy to read.

\section{Concrete corrosion - concrete protection}

\section{by Imre Biczók}

Published by Akadémiai Kiadó, Publishing House of the Hungarian Academy of Sciences, Budapest, 1964 (English edition). pp. 543.

There are so few books written in English about chemical aspects of concrete that any new book is eagerly studied by chemists and engineers who are interested in this subject. The book which is the subject of this review is over 500 pages long and therefore potentially a most useful work. Its value however is, in the opinion of this reviewer, much less than its length might suggest. The book was originally written in Hungarian and published in 1955. The English version appeared in 1964 and, although this version con- 
tains references to papers published as recently as 1962, it cannot be said to be truly up-to-date. If a book of this kind is to be useful it must either be exhaustive, and so serve as a reference book for the expert, or be a critical review which can serve as a text-book for the non-expert. This book is neither. A great deal of work and speculation on cement chemistry is reported but it is not a representative selection of current views and no attempt appears to have been made to select what is obviously the more important material. For these reasons the book cannot be recommended as a guide for civil engineers who are seeking an authoritative text-book. It is, nevertheless, despite its many defects, useful for the expert in that it includes much information not easily accessible to those persons unable to read East European languages. Although West European work is reported, the author seems more familiar with Hungarian and Russian work and much of the detail relates to materials of only local and limited importance.

The book contains five chapters.

\section{I: Basic materials of concrete}

The account of the chemistry of cements is in many respects quite incorrect; for example, the following statements are made:

" . . at the Symposium on the Chemistry of Cement, Washington 1960, several authorities arrived at the conclusion that no clear phases exist in technical cement clinker."

"It has been established further that the aluminates are distributed to tricalcium silicate, dicalcium silicate, the ferrite phase and the residual melt to a great extent, so that most Portland cement clinkers contain no tricalcium aluminate at all, or in negligibly small quantities only."

\section{II: Ground water}

This chapter gives a useful guide to ground-water sampling.

\section{III: Corrosion and protection of concrete}

This chapter comprises about half the book and examines in great detail the aggressive effect on con- crete of a wide range of chemicals. Much of the chapter is taken up with quotations of specifications and of recipes for precautions to be taken to combat aggressive liquors, in particular, sulphate solutions. It is difficult to see the value of such a lengthy treatment unless some firm recommendations are made at the end and this generally the author does not do, so that the reader is left to draw his own conclusions from a mass of conflicting information. Where conclusions are drawn they are so spare as to be useless, thus:

"Summarizing, it can be established that-neglecting particular solutions-the corrosion of concrete in solutions containing magnesium can be retarded by the following methods:

1. By the use of a suitable cement;

2. By making a dense concrete;

3. By protection of the concrete surface (paints, covers)."

\section{$I V$ : Factors increasing or reducing corrosion}

\section{$V:$ Detailed discussion of protective measures against corrosive effects}

These chapters are marred by the uncritical inclusion of references to a variety of materials under their trade names only.

To summarize, this volume has its value for the expert because it contains a great deal of published information about the corrosion of concrete but the selection is completely uncritical and unrepresentative and the reader must exercise his own judgement about what is valueless. It is not a book for the engineer seeking guidance with everyday problems of concrete construction.

The printing and binding of the book are excellent and the misprints comparatively few but although the author has generally been very well served by his translator, there are some odd sentences, as the following quotations will indicate:

"Wine is thus by no means indifferent to concrete."

"As far as the other components of cement are concerned, it should be pointed out that a higher sulphuric acid content involves increased susceptibility to sulphate attack." 